\title{
Precopulatory mate guarding by the male green chafer, Anomala albopilosa sakishimana Nomura (Coleoptera: Scarabaeidae)
}

\author{
Norio Arakaki, ${ }^{1, *}$ Mitsunobu Kishita, ${ }^{1}$ Atsushi Nagayama, ${ }^{1}$ Midori Fukaya, ${ }^{2}$ Hiroe Yasui, ${ }^{2}$ \\ Toshiharu AKIno, ${ }^{2}$ Yoshio Hirai ${ }^{2}$ and Sadao WAKAMura ${ }^{2}$ \\ ${ }^{1}$ Okinawa Prefectural Agricultural Experiment Station; Naha, Okinawa 903-0814, Japan \\ ${ }^{2}$ Laboratory of Insect Behavior, National Institute of Agrobiological Sciences (NIAS); Tsukuba 305-8634, Japan
}

(Received 12 November 2003; Accepted 7 April 2004)

\begin{abstract}
Mating behavior of the green chafer Anomala albopilosa sakishimana Nomura (Coleoptera: Scarabaeidae) was observed in Miyako Island, southwestern Japan from 28 to 29 May 2003. Females and males were present on patches of the beach naupaka, Scaevola sericea Vahl, throughout this time and showed clumped distribution within the patches. Males were observed to mount the backs of females for several hours during a day and successfully defend females from intruding males. Copulations took place only from 19:00 to 20:00 (JST) and most frequently at 19:40 (light intensity: $241 \mathrm{x}$ ). Mean copulation duration was $18.1 \pm 2.6$ min (mean $\pm \mathrm{SD}, N=16$ ). After mating, both sexes remained on the same leaf to feed. When females guarded by males were collected before mating time and subsequently reared in the laboratory, about $65 \%$ (11/17) laid fertilized eggs. This indicated that most of the females mounted by males are not virgin. In laboratory observations, several females mated more than once on different days, indicating $A$. $a$. sakishimana females are polyandrous. Since mounted males successfully defended the females from intruding males in the laboratory, long-lasting mounts appear to comprise precopulatory mate-guarding behavior. This is the first record of precopulatory mate guarding in scarab beetles.
\end{abstract}

Key words: Mate guarding; mating behavior; scarab beetle; green chafer; Anomala albopilosa sakishimana

\section{INTRODUCTION}

Among white grubs associated with sugar cane in the Ryukyu Islands of Japan, Anomala albopilosa (Hope) is considered to be one of the most destructive (Azuma and Oshiro, 1967; Nagamine, 1980a, b). In the Ryukyu Islands, A. albopilosa is divided into four subspecies (Takahashi, 1997): $A$. a. gracilis Schonfeldt occurring in Amami-Oshima Is., Tokunoshima Is., and Tokara Isles.; $A$. $a$. yashironi Sawada in Yoron Is., Okinoerabu Is., Okinawa Is. and Kume-jima Is.; A. a. sakishimana in Ishigaki Is., Iriomote Is., Miyako Is., Hateruma Is., Irabu Is. and Shimoji Is.; and A. a. yonaguniana Nomura in Yonaguni Is. Larvae of these four subspecies feed on the roots of sugar cane and consequently cause wilting and deterioration of stalks.

Mate guarding is understood in the context of male mating strategies (Thornhill and Alcock, 1983). Postcopulatory mate guarding behavior is well known in males of many insect species (Thornhill and Alcock, 1983; Alcock, 1994). In the scarab beetle, postcopulatory mate guarding has been reported only in the oriental beetle Exomara orientalis (Facundo et al., 1999). Parental care occurs in Kheper platynotus (Sato and Hiramatsu, 1993) and Onthophagus binodis (Cook, 1988), but is not included in this category.

Precopulatory mate guarding behavior is known in various beetles, including some cicindellids, staphylinids, and cerambycids (Parker, 1970), tenebrionids (Ferguson, 1992), curculionids (Thornhill and Alcock, 1983), as well as other insect taxa, the grasshopper Locusta migratoria (Parker and Smith, 1975), certain flies (Tarshis, 1958; Ward, 1983) and a veliid water-strider (Kellen, 1959). These males grasp potential mates and do not let go for many hours or even days.

In this paper, we report the precopulatory mate guarding behavior of $A$. a. sakishimana from field

\footnotetext{
* To whom correspondence should be addressed at: E-mail: arakkinr@pref.okinawa.jp DOI: 10.1303/aez.2004.455
} 
and laboratory observations.

\section{MATERIALS AND METHODS}

Spatial distribution patterns of adults on the host plants. Field studies were conducted on seven coastal plant patches of the beach naupaka Scaevola sericea Vahl growing at Nishi-HennaZaki on the northern cape of Miyako Is., Okinawa on 25 June 2003. We examined spatial distribution patterns of $A$. a. sakishimana adults on $S$. sericea plants along the pavement. Only one side of plants (ca. $1 \mathrm{~m}$ in half width) facing the pavement and the outward of the plants (leaves and beetles exist only on the outward of the plants) was studied. Spatial distribution was defined by quadrates $30 \mathrm{~cm}$ high $\times 100 \mathrm{~cm}$ wide. The spatial distribution patterns of adults on the host plants was analyzed by Morishita's $I_{\delta}$ index (Morishita, 1959). The $I_{\delta}$ index is expressed as the following equation:

$$
I_{\delta}=n \frac{\sum_{i=1}^{n} x_{i}\left(x_{i}-1\right)}{N(N-1)}
$$

where $n=$ number of quadrates, $N=$ total number of adults, $x_{i}=$ number of individuals of $i$ th quadrate. $I_{\delta}>1$ is the aggregation distribution, $I_{\delta}=1$ indicates a Poisson distribution and $I_{\delta}<1$ a uniform distribution.

Mating behavior of $A$. a. sakishimana in the field. Mating behavior of $A$. a. sakishimana was observed on patches of $S$. sericea at Nishi-HennaZaki on 28 May 2003. The onset and termination times of copulation in A. a. sakishimana on $S$. sericea plants was examined along ca. $20 \mathrm{~m}$ of pavement at intervals of 10 or $15 \mathrm{~min}$ from 16:30 to 20:30 (Japan Standard Time). When females mounted by males were found on the plants, the nearby leaf was marked with a numbered adhesive label.

The virginity of females mounted by males was ascertained through collection before mating time on 29 May 2003. Seventeen females mounted by males were collected and reared in plastic cups $(300 \mathrm{ml})$ with soil and a $S$. sericea leaf as food in the laboratory. Eggs laid were kept with a moistened piece of cotton in Petri dishes to check for hatchability. Adults were randomly collected around 12:30 on 29 May to obtain indices of sex ratio in the wild population. Temperature and wind velocity were measured at $1.5 \mathrm{~m}$ above the ground every 10 or $15 \mathrm{~min}$ from $16: 30$ to 20:00.

Daily mating behavior in the laboratory. About one hundred larvae of A. a. sakishimana were collected at a harvested sugar cane field in Gusukube, Miyako Is. by excavating stools with a shovel from 5 to 7 February 2003. These larvae were individually reared on pieces of potato $(1 \mathrm{~cm} \times 1 \mathrm{~cm} \times 1 \mathrm{~cm})$ in plastic cups $(80 \mathrm{ml})$. The cups contained a mixture of soil and leaf mold (1:1 in volume) at $25^{\circ} \mathrm{C}$ under natural light conditions in the laboratory of the Okinawa Prefectural Agricultural Experiment Station at Naha, Okinawa Is. Adults used in this experiment emerged from 3 to 8 June. Emerged adults were kept in the same cups for one week. Thereafter, they were sexed and kept individually in plastic cups of the same size with $S$. sericea leaves at $25^{\circ} \mathrm{C}$ and natural light conditions for one more week.

The beetles were numbered with an oily dye on their elytra (using felt-tip pens, Mitsubishi Paint Co., Ltd.) one day before the experiments (see Fig. 1). Six groups of five females each were confined on the day of experiments in six transparent plastic boxes $(36 \times 22 \times 22 \mathrm{~cm})$. These boxes were placed on the table near a north window. The plastic boxes contained a detached shoot $(10 \mathrm{~cm}$ long) of $S$. sericea with six or seven leaves. Five males each were introduced into each plastic box at 11:00 $(N=4)$ or 23:00 $(N=2)$ on 20 June 2003. Mating behaviors of the beetles were observed thereafter at 10 or 15 -min intervals. Light intensity was measured at the upper surface of the plastic box. A dimmed red light was used for visual observation during the dark period.

\section{RESULTS}

\section{Spatial distribution of $A$. a. sakishimana in the} field

Morishita's $I_{\delta}$ indices for seven $A$. a. sakishimana populations found on coastal patches of $S$. sericea plants are shown in Table 1. All the values were greater than 1 and the values were significant for all populations $(p<0.01, \quad F$-test $)$, showing clumped distributions.

Mean plant height of $S$. sericea in the survey area was $160 \pm 26 \mathrm{~cm}$ (mean $\pm \mathrm{SD}, N=52)$. A. $a$. sakishimana beetles showed a tendency to stay at 
Table 1. Spatial distribution of A. a. sakishimana adults on patches of Scaevora sericea at Nishi-Henna-Zaki, Miyako Is., Okinawa (25 June 2003)

\begin{tabular}{ccccccc}
\hline Colony & Length of patches (m) & No. of quadrats & No. of adults & $I_{\delta}$ & $F$ & $p$ \\
\hline 1 & 26 & 141 & 24 & 7.2 & 2.0 & $<0.01$ \\
2 & 18 & 102 & 19 & 13.1 & 3.2 & $<0.01$ \\
3 & 18 & 95 & 25 & 3.8 & 1.7 & $<0.01$ \\
4 & 17 & 35 & 23 & 5.4 & 3.8 & $<0.01$ \\
5 & 18 & 101 & 53 & 4.5 & 2.8 & $<0.01$ \\
6 & 10 & 57 & 28 & 2.4 & 1.7 & $<0.01$ \\
7 & 5 & 17 & 7 & 4.9 & 2.4 & $<0.01$ \\
\hline
\end{tabular}

${ }^{\text {a }}$ Quadrate size: $30 \mathrm{~cm}$ in height $\times 100 \mathrm{~cm}$ in width.
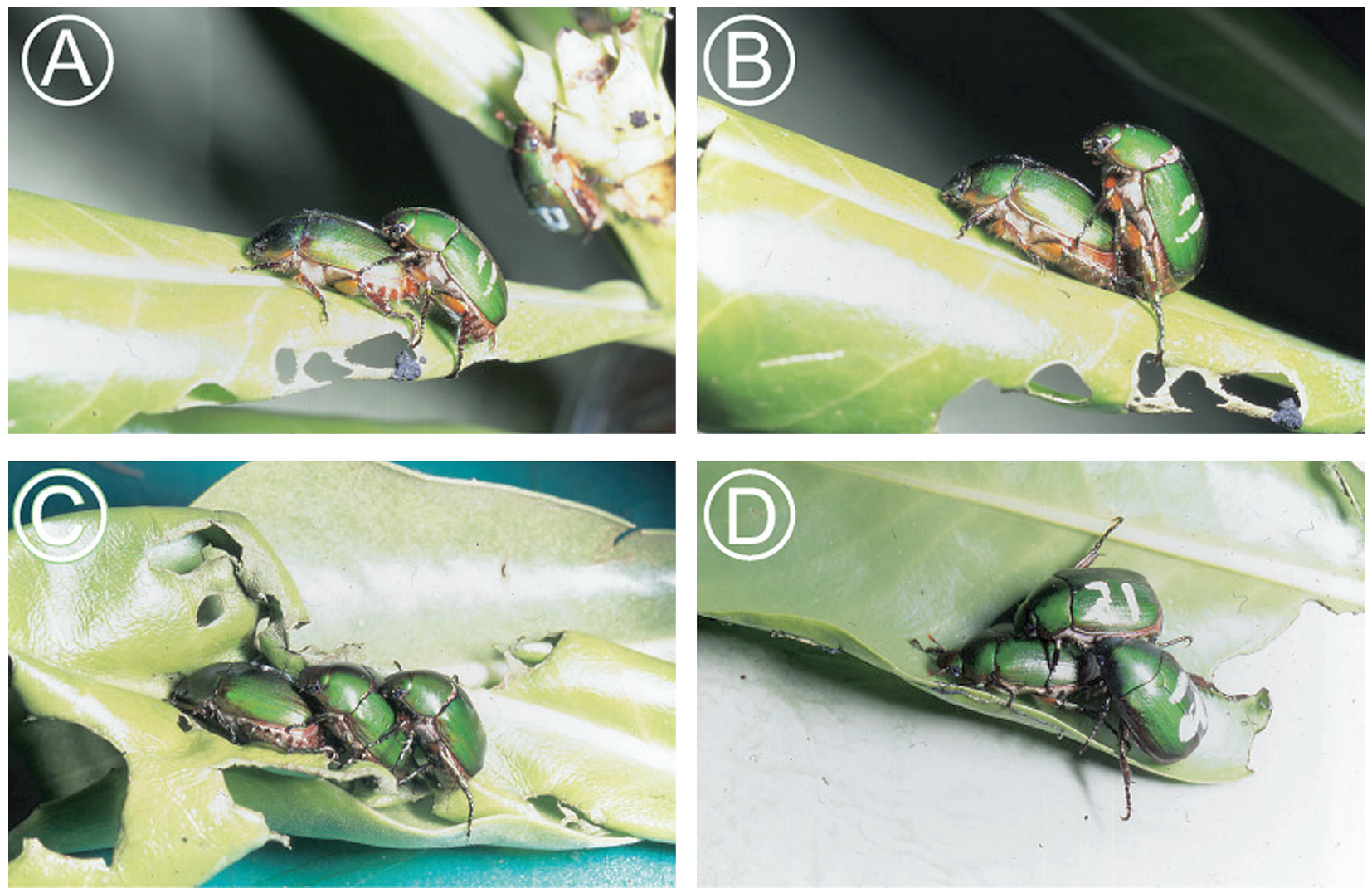

Fig. 1. Mating behaviors in A. a. sakishimana. A: Male (right) gripping the back of a female (left) using his forelegs firmly in a "half mount", B: Female (left) and male (right) in copulation, C: Second male (right) trying to dislodge the first male (center) by climbing on top of the first male, D: Second male (right) wedges himself between the pair.

the canopy level (120-150 cm, Fig. 2).

\section{Mating behavior of $A$. a. sakishimana observed in the field}

In the field, pairs of female and male were found in a copulatory position in which the male grasped the lateral edges of the female elytra with his forelegs (using specially modified forepretarsi) firmly in a "half mount" posture, but no genital contacts were observed (see Fig. 1A). Copulations (see Fig. 1B) were observed around 19:00 except for several cases immediately after male introduction (Fig. 3). When a second male intruded a pair to attempt to dislodge the first male (see Fig. $1 \mathrm{C}, \mathrm{D})$, the latter never released the female and prevented the rival mount in struggles of about $5 \mathrm{~min}$.

Before the start of field observations at 16:30 17:00, 20 pairs of females mounted by males were 
found. Although males held females for many hours, copulation did not take place until the evening (Fig. 3). The first copulation was observed at 19:00 when light intensity was 2,4001x. The highest frequency of copulations occurred at 19:40 when light intensity was $24 \mathrm{~lx}$. The last copulation was observed at 20:00 when light intensity was less

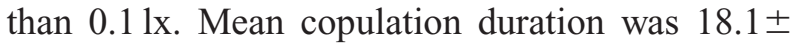
2.6 min (mean $\pm \mathrm{SD}, N=16$ ). Twenty-one pairs of females mounted by males were found to copulate in the evening. During copulation, the male moved his body posteriorly while arching his abdomen to insert his aedeagus. Neither the female nor male consumed food during copulation. Afterwards, both sexes remained on the leaf and fed during the night.

Among 17 females guarded by males in the field, 11 females laid fertilized eggs and three laid unfertilized eggs. The other three females died without oviposition. A total of 83 adults, including eight

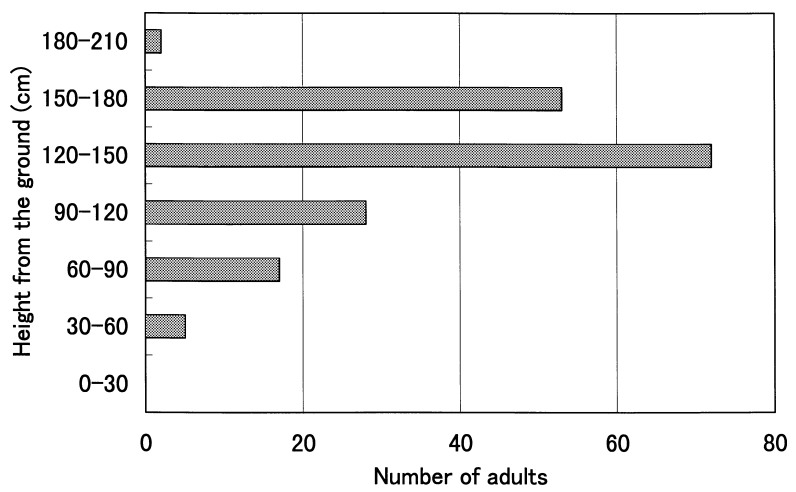

Fig. 2. Distribution of settling height of A. a. sakishimana adults on S. sericea patches (25 June 2003, Miyako Is.). pairs, were collected on 29 May 2003. The number of females and males were 44 and 39, respectively. The sex ratio was not significantly different from the $1: 1$ ratio $\left(p>0.5, \chi^{2}\right.$ test). Mean temperatures in the field were 26.7 and $27.5^{\circ} \mathrm{C}$ and mean wind velocities were 2.7 and $1.6 \mathrm{~m} / \mathrm{s}$ on 28 and 29 May, respectively.

\section{Daily mating behavior in the laboratory}

When males were introduced into plastic boxes that contained virgin females at 11:00, they actively walked on the bottom of the box or on the plants. Within two hours after male introduction, $60 \%(12 / 20)$ of the females present had been mounted. Three other females were mounted by 18:00 (Fig. 4). Most males approached the females

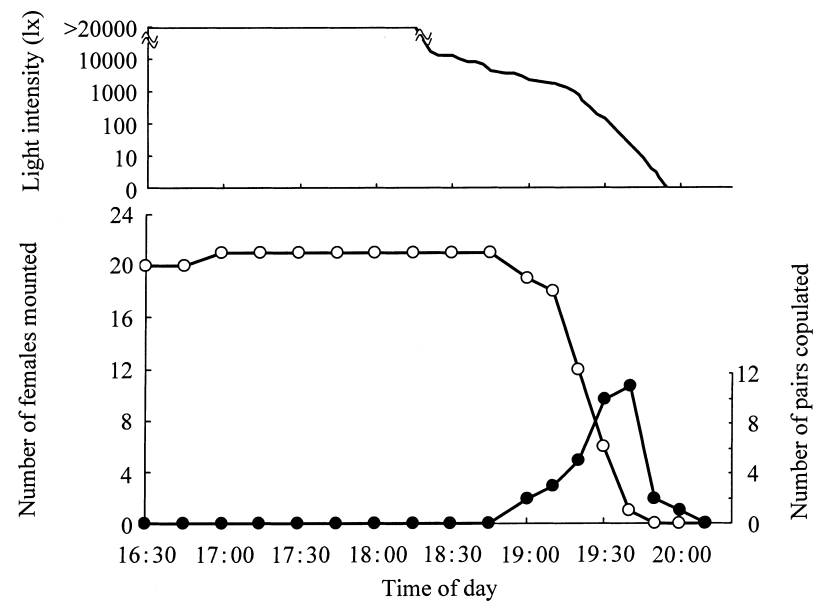

Fig. 3. Holding and mating behaviors in A. a. sakishimana in the field (Miyako Is., 2003). Bottom: Number of females mounted by males (open circle) and number of pairs in copulation (solid circle). Top: Light intensity.

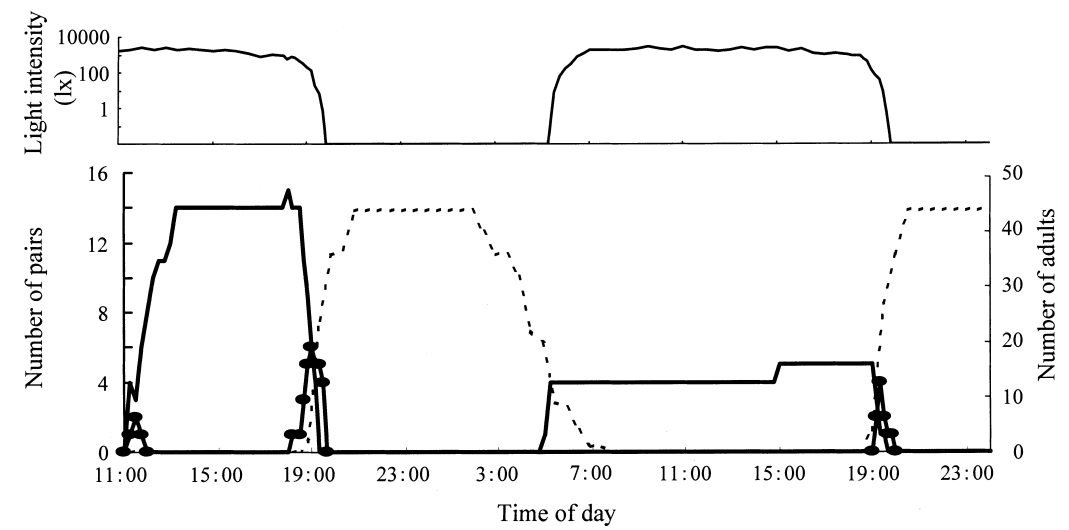

Fig. 4. Holding and mating behaviors in virgin females and males of $A$. a. sakishimana in the laboratory $(N=4)$. Bottom: number of pairs in which male mounted a female (solid line) and in copulation (solid circle) and number of adults feeding (dotted line). Top: Light intensity. Males were introduced into the plastic boxes containing females at 11:00 on 20 June 2003. 
at the caudal end and then immediately grasped the lateral edges of the hind part of the elytra with the forelegs. The middle part of female hind legs were grasped by the male middle legs. When a female became passive, the male released his middle legs but continued grasping the elytra with his forelegs. The pairs stayed on plants in this position for many hours during the daytime and copulated in the evening. The first copulation was observed at 18:10 when light intensity was $590 \mathrm{~lx}$. The highest frequency occurred at 19:00 when light intensity was $2201 x$. The last copulation was observed at 19:30 when light intensity was $7.4 \mathrm{~lx}$.

Among 20 females, 2 females copulated within $30 \mathrm{~min}$ after introduction of males. These males never released the females even after mating. They held the same females continuously and copulated again in the evening (Fig. 4).

Early after introduction of the males into the boxes, males mounting on the backs of other males were observed in three boxes. The other males frequently struggled to dislodge the upper male which firmly grasped his partner's elytra with his forelegs, and hind legs with his middle legs. These male- male pairs stayed in this state until evening. This type of homosexual mounting was observed only in the first of the three days.

Among 20 females used in this experiment, 15 (75\%) copulated during the first day of male introduction, and $5(25 \%)$ and $2(10 \%)$ copulated on the second and third days, respectively (Table 2). Among five females copulating on the second day, three were virgin and the remaining two mated on the first day. On the third day, two females had already mated on the first day. Two virgin females never accepted mounting or copulation by males during the three-day observation period. These unreceptive females tried to dislodge the males by rapid walking, or kicking with their hind legs one after the other alternately. These mate refusal behaviors were probably due to female sexual immaturity.

After mating, both sexes remained on the leaf to feed. Both females and males fed during the night, but stopped feeding in the early morning.

When males were introduced into the plastic boxes containing females at 23:00, they engaged in feeding during the night (Fig. 5). The males were

Table 2. Daily frequency of copulations when females and males were confined together in plastic boxes for three days from June 20 to June 22

\begin{tabular}{|c|c|c|c|c|c|c|c|c|c|c|c|c|c|c|c|c|c|c|c|c|}
\hline & \multicolumn{20}{|c|}{ Individual discriminating codes of females } \\
\hline & 1 & 2 & 3 & 4 & 5 & 6 & 7 & 8 & 9 & 10 & 11 & 12 & 13 & 14 & 15 & 16 & 17 & 18 & 19 & 20 \\
\hline $\begin{array}{l}\text { First day } \\
\text { Second day } \\
\text { Third day }\end{array}$ & $\bullet$ & • & - & • & • & $\bullet$ & - & • & & $\bullet$ & $\bullet$ & $\bullet$ & • & $\bullet$ & $\bullet$ & - & $\bullet$ & • & & $\bullet$ \\
\hline
\end{tabular}

: copulated.

Five females and five males were confined in each box. Four replications were done.

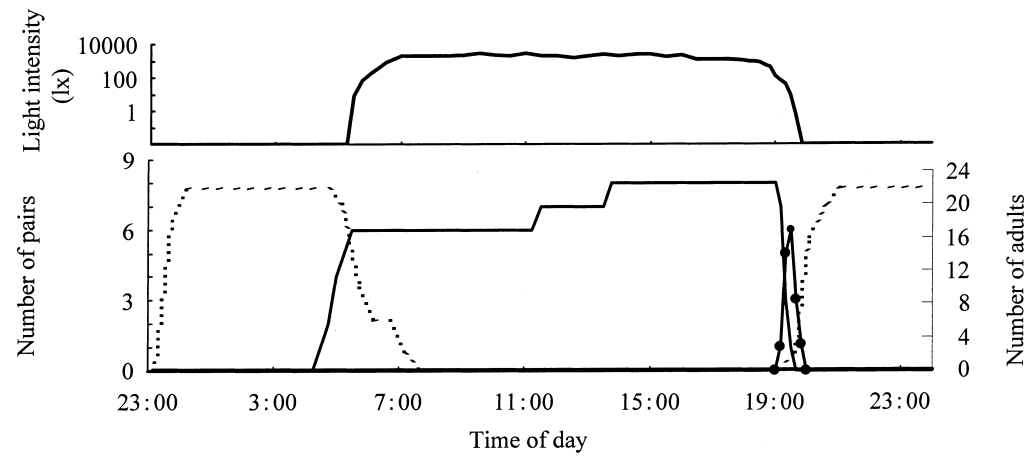

Fig. 5. Holding and mating behaviors in virgin females and males of $A$. a. sakishimana in the laboratory $(N=2)$. Males were introduced into the plastic boxes containing females at 23:00 on 20 June 2003. 
observed to search actively and mount the females at dawn. These males continuously mounted females during the daytime, and copulated in the evening between 19:10 and 19:50. The highest frequency of copulation occurred at 19:30 when light intensity was $9.1 \mathrm{~lx}$. Male-male pairs were also observed in this experiment.

When a second male tried to disrupt a pair, two maneuvers were employed: (1) climbing on top of the first male (Fig. 1C) and (2) wedging himself in between the pair (Fig. 1D). In all cases $(N=8)$, the first males successfully resisted the intrusions and successfully copulated in the evening (Fig. 1B).

\section{DISCUSSION}

We found $A$. a. sakishimana adults assembled on coastal patches of $S$. sericea plants at Nishi-HennaZaki in Miyako Is. in assemblages similar to those observed and reported for the black chafer Holotrichia loochooan loochooana (Kawamura et al., 2001) (Table 1). These two scarab beetles assembled only on $S$. sericea patches. H. $l$. loochooana adults settled on $S$. sericea plants only in the evening, however, A. a. sakishimana stayed on this plant all day long.

Twenty pairs of males mounted on females were found in the coastal $S$. sericea patches at the start of field observations (Fig. 3). The males were observed to simply mount the female backs without engagement of the genitalia (Fig. 1A) in a "passive phase" (Parker, 1970) or pairing in tandem (Setokuchi et al., 1984). Although males held females for long periods, copulation took place only in the evening (Fig. 3). A similar tendency was observed in the laboratory observations (Figs. 4 and 5). After mating, both females and males stayed on the leaf to feed throughout the night and males mounted females again in the early morning and then copulated in the evening (Fig. 4). These laboratory and field observations clarified the following daily behaviors are adopted under field conditions; 1) Males actively search for receptive females in early morning and mount them, 2) males continue to remain mounted on females during the day, 3) copulation occurs in the evening, 4) the pair separates, 5 ) both sexes feed during the night.

If males are actually guarding their mates from rival males, there should be at least occasional competition for other males to mount the females
(Thornhill and Alcock, 1983). In the field observations, one male unsuccessfully tried to dislodge the mounted male by entering between the pair. Several contests were also observed in the laboratory experiments (Fig. 1C, D). These observations indicate that long-lasting grips on females by males are a form of precopulatory mate guarding. Our findings are the first record of precopulatory mate guarding in scarab beetles, although Setokuchi et al. (1984) described "pairing in tandem" that was observed in soybean fields before mating in $\mathrm{A}$. rufocuprea Motschulsky. We speculate the "pairing in tandem" in this species is also mate guarding by males.

Behavioral traits have costs and benefits in terms of their effects on reproductive success (Thornhill and Alcock, 1983). If mate guarding results in large benefits or requires low costs, forms of mate guarding should evolve. As a result of mate guarding in A. a. sakishimana, most of the mounting males successfully copulated (Figs. 3-5) and thwarted rivals. Therefore, mate guarding in A. a. sakishimana should increase the reproductive success of males.

On the other hand, the trait also has costs, including time spent riding one female, which 1) cannot be used to find additional mates, 2) reduces feeding time, and 3 ) increases the danger of predation. These may be considered as potential costs. $A$. a. sakishimana females became sexually receptive only during restricted time periods, i.e. only for about one hour in the evening. Males required at least $18.1 \mathrm{~min}$ for mating and this time is presumably the minimum necessary for insemination. During the limited period of time when females become receptive, the occupation by males may be rapid. Under these circumstances it may be almost impossible to get additional mates in a single day. Female and male $A$. a. sakishimana feed during the night, but mate guarding behavior occurs only in the day. Therefore, this cost would not be critical. We did not see any predation on $A$. a. sakishimana throughout our observations in the field. The cost of mate guarding in A. a. sakishimana males appears to be low.

We collected 17 females guarded by males in the field and found that 11 of them laid fertilized eggs after laboratory rearing. In a separate laboratory observation, several females mated more than once on different days (Table 2). This indicates that 
mated females are still receptive to additional mates. In a congeneric species, females of Anomala caprea Hope are known to mate repeatedly on the leaves of chestnut trees (Inou and Takai, 1984). Therefore, A. a. sakishimana females may also be polyandrous. Although the sex ratio of $A$. a. sakishimana was found to be almost 1:1 in this field study, most males appear to be sexually active and most females were mated. This leads to the probable male bias of the operational sex ratio (the ratio of sexually active males to sexually active females). Generally, a male's sperm precedence (priority in fertilization over other males) is greatly influenced by the order of mating in multiple copulations (Thornhill and Alcock, 1983). Sperm precedence in $A$. a. sakishimana is an important future topic.

As to the evolution of precopulatory mate guarding, Ridley (1983) has argued that such behavior has evolved only in species in which females are receptive to copulation only during very short and predictable periods. Generally most scarab beetles are known to copulate only in the evening, e.g. the black chafer $H$. l. loochooana (Kawamura et al., 2001). They feed during the night and creep into the soil in the early morning. Adults of Dasylepida sp. appear from the soil and copulate in the evening. After copulation, they return to the soil immediately without taking food (unpublished data). These two scarab species have not developed precopulatory mate guarding behavior. In contrast, $A$. a. sakishimana stays on the $S$. sercea leaves throughout the day. This habit may also strongly relate to evolution of the precopulatory mate guarding behavior, because their behavior of staying on the plant all day should increase the rate of encounters between females and males. Furthermore, A. a. sakishimana aggregates on certain $S$. sericea patches so that females and males spend the day at close range. Under these sexually competitive circumstances for males, it would be advantageous the male to develop a hold on females in advance of rival males even though females do not become sexually receptive until the evening. Therefore this mate guarding behavior may have evolved in this beetle.

Migration of the lineate chafer, Mimela testaceipes, from sward to forest has been observed (Torikura, 1991). Forests are important sites for feeding, mating and egg-development for newly emerged adults. Gravid females then returned to the sward for oviposition. Similar migration has been observed in the cupreous chafer Anomala cuprea, between peanut fields and chestnut fields (Inou and Takai, 1984). In the black chafer H. $l$. loochooana, Kawamura et al. (2001) suspected migration from sugar cane fields to coastal plant patches of the beach naupaka, S. sericea. This migration may also occur in $A$. a. sakishimana. Colonies of $S$. sericea grow only in rocky coastal areas with shallow upper soils. Such areas are not good habitats for $A$. a. sakishimana larvae. This economically important species spends the larval and pupal stages in sugar cane fields (Nagamine, 1980a, b). Emergence of A. a. sakishimana adults from the ground in the sugar cane field starts in mid-May, peaking late May and terminating in late July on Miyako Is. (Higa et al., 1978). Emerged adults are thought to move to the coastal areas and spend several days on patches of $S$. sericea. During this coastal phase, females feed voraciously on $S$. sericea and mate repeatedly. After several days, gravid females probably return to the sugar cane fields to oviposit. Migration of A. a. sakishimana between the fields and coastal areas should be clarified in future studies.

\section{ACKNOWLEDGEMENTS}

We thank Chio Hayashi and Naoki Taniai for their technical and secretarial assistance. Thanks are also due to Masato Ishimine, Akira Oyafuso and Tsuneo Kinjo of the Miyako Branch of the Okinawa Agricultural Experiment Station for their kind support with the field experiments. The manuscript was improved by Serge Glushkoff.

\section{REFERENCES}

Alcock, J. (1994) Postinsemination associations between males and females in insects: the mate-guarding hypothesis. Annu. Rev. Entomol. 39: 1-21.

Azuma, S. and Y. Oshiro (1967) Studies on the insect pests of sugar cane in the Ryukyu Islands. 2. Catalogue of insect pests. Bull. Ryukyu Agric. Exp. Stn. 3: 63-75 (in Japanese).

Cook, D. (1988) Sexual selection in dung beetles. II. Female fecundity as an estimate of male reproductive success in relation to horn size, and alternative behavioural strategies in Onthophagus biondis Thunberg (Scarabaeidae; Onthophagini). Aust. J. Zool. 36: 521-532.

Facundo, H. T., C. E., Jr., Linn, M. G. Villani and W. L. Roelofs (1999) Emergence, mating, and postmating behaviors of the oriental beetle (Coleoptera: Scarabaeidae). J. Insect Behav. 12: 175-192.

Ferguson, J. W. H. (1992) Mate following in desert tenebri- 
onid beetles revisited: why do males spend so much time in courtship? J. Kansas Entomol. Soc. 65: 125-133.

Higa, T., R. Teruya and T. Tamaki (1978) Ecological notes on the occurrence of the adults Anomala albopilosa sakishimana Nomura (Coleoptera: Scarabaeidae) on Miyako Is. Proc. Assoc. Pl. Prot. Kyushu 24: 132-135 (in Japanese).

Inou, M. and A. Takai (1984) Occurring conditions of Anomala cuprea Hope and movement of adults. Plant Protect. 38: 395-398 (in Japanese).

Kawamura, F., N. Arakaki, M. Kishita and Y. Sadoyama (2001) Mating behavior of the black chafer, Holotrichia loochooana loochooana (Coleoptera: Scarabaeidae). Entomol. Sci. 4: 223-227.

Kellen, W. R. (1959) Notes on the biology of Halovelia marianarum Usinger in Samoa (Veliidae; Heteroptera). Ann. Entomol. Soc. Am. 52: 53-62.

Morishita, M. (1959) Measuring of the dispersion of individuals and analysis of the distributional patterns. Mem. Fac. Sci. Kyushu Univ. Ser. E (Biol.) 2: 215-235.

Nagamine, M. (1980a) On the fauna of white grubs inhabiting in sugarcane fields in Okinawa. Bull. Ryukyu Agric. Exp. Stn. 5: 53-64 (in Japanese with English summary).

Nagamine, M. (1980b) Fauna of white grubs in sugarcane fields of Okinawa and their importance as pests of sugarcane. Proc. Int. Soc. Sugar Cane Tech. 17: 1680-1685.

Parker, G. A. (1970) Sperm competition and its evolutionary consequences in the insects. Biol. Rev. 45: 525-567.

Parker, G. A. and J. L. Smith (1975) Sperm competition and the evolution of the precopulatory passive phase behav- iour in Locusta migratoria migratorioides. J. Ent. (A) 49: $155-171$.

Ridley, M. (1983) The Explanation of Organic Diversity: The Comparative Methods and Adaptations for Mating. Clarendon Press, Oxford. 277 pp.

Sato, H. and K. Hiramatsu (1993) Mating behavior and sexual selection in the African ball-rolling scarab, Kheper platynotus Bates (Coleoptera; Scarabaeidae). J. Nat. Hist. 27: 657-668.

Setokuchi, O., M. Kobayashi and K. Oashi (1984) Studies on the ecology of soybean beetle, Anomala rufocuprea Motschulsky (Coleoptera: Scarabaeidae). Bull. Kagoshima Agric. Exp. Stn. 12: 45-72 (in Japanese with English summary).

Takahashi, T. (1997) Systematic catalog of Scarabaeoidea from Japan. Kiberi-hamushi 25: 1-89 (in Japanese).

Tarshis, I. B. (1958) New data on the biology of Stilbometopa impressa (Bigot) and Lynchia hirsuta Ferris (Diptera: Hippoboscidae). Ann. Entomol. Soc. Am. 54: 95-105.

Thornhill, R. and J. Alcock (1983) The Evolution of Insect Mating Systems. Harvard University Press, London. $545 \mathrm{pp}$.

Torikura, H. (1991) On the flight of Mimela testaceipes between sward and forest, in relation to its internal conditions (Coleoptera, Scarabaeidae). Jpn. J. Entomol. 59: 199-211 (in Japanese with English summary).

Ward, P. (1983) The effects of size on the mating behavior of the dung fly Sepsis cynipsea. Behav. Ecol. Sociobiol. 13: $75-80$. 